\title{
Diversidad genética de accesiones de la familia Caricaceae en el sur de Ecuador
}

\author{
Denisse F. Peña ${ }^{1}$, Paulina G. Villena ${ }^{1}$, Ángel J. Aguirre ${ }^{1,2}$, Carlos Jiménez Merino ${ }^{3}$ \\ ${ }^{1}$ Facultad de Ciencias Agropecuarias, Universidad de Cuenca, Cuenca, Ecuador. \\ ${ }^{2}$ Proyecto PROMETEO, Secretaría de Educación Superior, Ciencia, Tecnología e Innovación, Quito, \\ Ecuador. \\ ${ }^{3}$ Estación Experimental del Austro, Instituto Nacional Autónomo de Investigaciones Agropecuarias \\ (INIAP).
}

Autor para correspondencia: denisse.pena@ucuenca.edu.ec

Fecha de recepción: 20 de febrero 2017 - Fecha de aceptación: 23 de mayo 2017

\section{RESUMEN}

Se estudió la diversidad genética de 78 accesiones de la familia Caricaceae recolectadas en las provincias de Azuay, Cañar, Loja, Zamora Chinchipe y El Oro, al sur de Ecuador, de las especies Vasconcellea candicans, V. goudotiana, V. longiflora, V. microcarpa, V. monoica, V. omnilingua, V. palandensis, V. stipulata, V. parviflora, V. sp., V. $x$ heilborne, $V . x$ heilborne cv pentagona, $V . x$ heilborne cv chrysopetala, Carica papaya, Jaracatia digitata y J. spinosa, a través de la amplificación de los ADN con 14 iniciadores aleatorios de las series AA, AC, AM y AN de Operon Technologies Inc. Los iniciadores RAPD utilizados para la amplificación produjeron un total de 76 fragmentos polimórficos con tamaños entre 368 y 2102 pares de base (pb). Los análisis de cluster y coordenadas principales agruparon las accesiones de cada especie entre ellas y fueron consistentes en su mayoría con otros estudios previos. El dendrograma separó claramente los tres géneros, sin embargo, con base a estos resultados, estudios y observaciones morfológicas, se sugiere la posible creación de un nuevo género que agrupe a los materiales de Vasconcellea candicans. Además, los autores apoyan la hipótesis de denominar a los materiales colectados en la zona de Molleturo como un nuevo taxón del género Vasconcellea. Como en otros trabajos, los resultados sugieren posibles eventos de hibridación ínterespecífica dentro del género Vasconcellea.

Palabras clave: Identidad genética, Vasconcellea, Carica papaya, Jaracatia, RAPDs.

\begin{abstract}
The genetic diversity of 78 accessions of the Caricaceae family collected in the provinces of Azuay, Cañar, Loja, El Oro and Zamora Chinchipe, south of Ecuador, was studied, including the species Vasconcellea candicans, $V$. goudotiana, V. longiflora, $V$. microcarpa, $V$. monoica, $V$. omnilingua, $V$. palandensis, V. stipulata, V. parviflora, V. sp., V. $x$ heilborne, $V . x$ heilborne cv pentagona, $V . x$ heilborne cv chrysopetala, Carica papaya, Jaracatia digitata y J. spinosa by DNA amplifications using 14 aleatory primers from AA, AC, AM and AN series of Operon Technologies Inc. The used RAPD primers produced 76 polymorphic fragments with sizes between 368 and 2102 base pairs (bp). The cluster and principal coordinate analysis grouped the accessions of each kind among them and the results were consistent with previous studies. The dendrogram separated clearly the three genera, however, based on these results, studies and morphological observations, the creation of a new genera that groups the Vasconcellea candicans accessions is suggested. Furthermore, the authors support the hypothesis of designating the materials collected in the Molleturo zone as a new taxón of the genera Vasconcellea. As in other studies, the results suggest possible events of interspecific hybridization within Vasconcellea genus.
\end{abstract}

Keywords: Genetic identity, Carica papaya, Vasconcellea, Jaracatia, RAPDs. 


\section{INTRODUCCIÓN}

Las Caricaceaes, una familia pequeña constituida por 6 géneros y 35 especies siendo el género Vasconcellea el más grande, de acuerdo a la clasificación realizada por Badillo (2000) consta de 20 especies y un híbrido, Vasconcellea $x$ heilbornii. Sin embargo, este hibrido también es considerado como especie a pesar de sus restricciones en la reproducción sexual. El análisis espacial de la riqueza de especies muestra claramente que Ecuador, Colombia y Perú son áreas de alta diversidad de Vasconcellea (Scheldeman, 2007, 2011). Ecuador tiene por lo menos 16 de las 21 especies descritas, por lo que es considerado como el centro de biodiversidad de Vasconcellea (Badillo, 1993, 1997, 2000; RomeijnPeeters, 2004). Estas especies son conocidas comúnmente como "papayas de montaña o de altura" (National Research Council, 1989) en parte por su parecido a la papaya Carica papaya y por otro lado debido a las preferencias ecológicas en zonas altas; crecen en los valles altos del Ecuador, sobre los 3000 m.s.n.m., están considerados como cultivos subexplotados aun cuando poseen características agronómicas importantes como resistencia a enfermedades, tolerancia al frío, sustancias proteolíticas, entre otras (Scheldeman et al., 2011), que podrían ser usadas en programas de mejoramiento genético (Badillo, 1971, 1993; Van Droogenbroeck et al., 2004; Scheldeman et al., 2011). En el Sur del Ecuador, en inventarios etnobotánicos de plantas comestibles silvestres y semidomesticadas, se ha observado una variabilidad desconocida entre y dentro de las especies del género Vasconcellea (Jiménez et al., 1999). Muchos de estos parientes silvestres son intercompatibles y se pueden polinizar cruzadamente para producir híbridos espontáneos en áreas donde la distribución de las especies es simpátrica (Badillo, 1971). El babaco (V. x heilbornii var. pentagona), considerado un híbrido natural estéril de V. stipulata y V. cundinamarcensis, es originario de las zonas altas del Ecuador (Horovitz \& Jiménez, 1976). Algunas especies de este género figuran en la lista roja de especies amenazadas tales como: $V$. horovitziana, V. omnilingua, V. palandensis, V. pulchra y V. sprucei (IUCN, 2003). Kyndt et al. (2005a) en su artículo indican que "observaciones personales en Ecuador sugieren que más especies de Vasconcellea están en peligro de extinción”, probablemente esto se deba a los altos índices de deforestación registrados en el país. Estudios dirigidos a supervisar, recopilar, conservar y aprovechar adecuadamente los recursos genéticos del Ecuador, así como ciertos hábitats de éstas y otras especies son imprescindibles.

Los marcadores moleculares de ADN constituyen una herramienta confiable ya que proporcionan estabilidad en la identificación de especies, ayudando a eliminar los inconvenientes de una selección basada en el análisis exclusivo del fenotipo, lo cual requiere observaciones muy exhaustivas de los organismos en los diferentes estadios de desarrollo. A menudo, los criterios utilizados carecen de definición y objetividad, y, en cualquier caso, son marcadores ambiguos debido a las influencias ambientales (Claros, 2002; Oliveira et al., 2011). Debido a las ventajas y a la simplicidad de la técnica de RAPD (Random Amplification of Polymorphic DNA), esta ha sido ampliamente aplicada en varios estudios de diversidad de plantas, por ejemplo, en estudios de genética de poblaciones, identificación taxonómica, construcción de mapas genéticos, huellas genómicas para la identificación de cultivares, y la determinación de híbridos. El método también ha sido empleado en la definición de core collection, en estudios de los orígenes de los híbridos, y en la reconstrucción de filogenia (Estrella et al., 1998).

Varios estudios de diversidad genética de Caricaceae se han realizado: RFLPs: Aradhya et al., 1999, Olson, 2002; AFLPs: Van Droogenbroeck et al., 2002, Ratchadaporn et al., 2007, Oliveira et al., 2011; PCR-AFLPs y PCR-RFLP: Van Droogenbroeck et al., 2004, Kyndt et al., 2005a; ITS nuclear y Secuencias plastidios: Kyndt et al., 2005b; Inter-Simple Sequence Repeats (ISSR): Carrasco et al., 2009; y Simple Sequence Repeats (SSR): Oliveira et al., 2010). Sin embargo, varios autores manifiestan que técnicamente los marcadores moleculares difieren en términos de costo, reproducibilidad, rapidez, cantidad de ADN necesaria, trabajo, y grado de polimorfismo (Oleas et al., 2013; Costa et al., 2016). El análisis RAPD es simple, rápido y tiene la capacidad de detectar polimorfismos extensos (Thormann et al., 1994), son sencillos de usar y no requieren el uso de materiales radioactivos (Williams et al., 1990). Souza et al. (2008), mediante un análisis comparativo, encontraron que los RAPD fueron eficaces en la evaluación de la genealogía de los materiales, mientras que la RSS fueron fundamentales para reconocer diferencias entre las características cuantitativas de los taxones. Aunque el nivel de polimorfismo revelado por la técnica RAPD puede ser menor que con otras, es más fácil de implementar y tiene un costo menor (Costa et al., 2016). 
El proyecto "Diversidad de Frutales Nativos Comestibles Solanaceae y Caricaceae, Fenología Usos y Recolección de Germoplasma en el Sur del País", financiado por el Programa de Modernización del Sector Agropecuario (PROMSA, 2003) y El Instituto Nacional de Investigaciones Agropecuarias (INIAP), colectó material de Carica, Jaracatia y Vasconcellea en estado silvestre y cultivado. Algunas accesiones de Vasconcellea poseían características morfológicas aún no descritas, razón por la cual se lo consideró como un posible nuevo taxón botánico. Además, se colectó una segunda especie que morfológicamente compartía características tanto de $V$. cundinamarcensis como del posible nuevo taxón, ambas en la Cordillera Occidental del Austro de Ecuador (INIAP, 2003). El presente trabajo buscó conocer las relaciones filogenéticas entre las accesiones registradas por el proyecto "Diversidad de frutales nativos comestibles Solanaceae y Caricaceae, fenología, usos y recolección de germoplasma en el sur del país" y evaluar la existencia de un posible nuevo taxón silvestre (Peña, 2005).

\section{MATERIALES Y MÉTODOS}

Este trabajo se desarrolló en el Laboratorio de Biología Molecular del Departamento Nacional de Recursos Fitogenéticos y Biotecnología (DENAREF-INIAP). Se utilizaron 78 accesiones recolectadas en las provincias de Azuay, Cañar, Loja, Zamora Chinchipe y El Oro, al sur de Ecuador de las especies $V$. candicans, $V$. goudotiana, $V$. longiflora, $V$. microcarpa, $V$. monoica, V. omnilingua, V. palandensis, $V$. stipulata, V. parviflora, V. sp, V. $x$ heilborne, $V . x$ heilborne $c v$ pentagona, $V . x$ heilborne $c v$ chrysopetala, Carica papaya, Jaracatia digitata y J. spinosa.

\subsection{Preparación de la muestra}

Se tomaron muestras foliares en estado inmaduro, estas fueron cuidadosamente conservadas y transportadas al laboratorio en fundas zip lock debidamente etiquetadas, en cada una de estas se adicionaron pequeños paquetes de gel de sílice, los cuales se revisaron y cambiaron diariamente hasta obtener un material totalmente seco. Cada una de las muestras secas fueron maceradas en morteros, en donde se adicionó $0.2 \mathrm{~g}$ de antioxidante bisulfito de sodio. Luego, $0.5 \mathrm{~g}$ de material macerado fue utilizado para cada una de las extracciones.

\subsection{Extracción del ADN}

El protocolo empleado fue una combinación de las técnicas de Ferreira \& Grattapaglia (1998) y Del Río \& Bambey tal como lo describen Yaguache \& Medina (2003). Cuando las muestras se mostraron contaminadas se sometieron a una purificación con el protocolo de Jhingan (1992).

\subsection{Cuantificación del ADN}

La cuantificación del ADN genómico se llevó a cabo en mini-geles de agarosa 1\%, mediante la comparación de los fragmentos de ADN obtenidos con los del estándar ADN Low Mass Ladder, luego de la electroforesis y la foto documentación, cada uno de los fragmentos fue evaluado asignándole un valor de concentración (Morillo, 2000; Morillo \& Miño, 2011). Se realizaron las diluciones pertinentes, a partir del valor obtenido en la cuantificación, para obtener una concentración final de $5 \mathrm{ng} / \mu \mathrm{l}^{1}$ en cada muestra diluida con TE $1 \mathrm{X}^{2}$.

\section{4. $\quad$ AP-PCR}

En base a estudios previos (Yaguache \& Medina, 2003), se seleccionaron los 14 iniciadores: AA-02, AA-04, AA-07, AA-11, AA-18, AC-01, AC-19, AM-04, AM-07, AM-09, AN-01, AN-15, AN-16, AN20. Las amplificaciones se realizaron colocando $3 \mu \mathrm{l}$ de cada muestra de ADN (5 ng/ $\mu$ l) en tubos PCR, en cada uno de ellos se adicionó $5.5 \mu \mathrm{l}$ de la solución de la mezcla de reacción que consta de: $2.2 \mu 1$

\footnotetext{
$1 \mathrm{ng} / \mu \mathrm{l}:$ nanogram/microlitro

2 TE 1X: 10 mM de Tris HCl y $1 \mathrm{mM}$ de EDTA, pH 8
} 
buffer PCR $5 \mathrm{X}$ (Tris pH8 $0.25 \mathrm{M}, \mathrm{KCl} 0.1 \mathrm{M}, \mathrm{MgCl}_{2} 6 \mathrm{H}_{2} \mathrm{O} 0.005 \mathrm{M}$, BSA $0.25 \%$, Ficoll $4000.75 \%$, Xylene Cyanole 0.05\%) (Morillo, 2000), $0.13 \mu \mathrm{l}$ de Taq polimerasa $\left(5 \mathrm{U} / \mu 1^{3}\right), 0.4 \mu \mathrm{l}$ de DNTPs $(2.5 \mathrm{mMc} / \mathrm{u}, \mathrm{MgCl} 0.025 \mathrm{M}), 2.3 \mu \mathrm{l}$ de agua ultrapura y $0.4 \mu \mathrm{l}$ del iniciador $\left(20 \mathrm{pmol}^{4}\right)$; la mezcla resultante fue cubierta con $10 \mu \mathrm{l}$ de aceite mineral para evitar la evaporación. Los tubos fueron debidamente tapados y colocados en un termociclador MJ Research PTC-100 con la siguiente programación: desnaturalización inicial a $94^{\circ} \mathrm{C}$ durante $5 \mathrm{~min}$, seguido por 40 ciclos de amplificación, una desnaturalización a $94^{\circ} \mathrm{C}$ durante 30 segundas, un alineamiento a $40^{\circ} \mathrm{C}$ durante 1 min, una extensión a $72^{\circ} \mathrm{C}$ durante $2 \mathrm{~min}$, una extensión a $72^{\circ} \mathrm{C}$ durante $7 \mathrm{~min}$, y finalmente una conservación a $4^{\circ} \mathrm{C}$ durante 5 min. Los productos de la amplificación se migraron en geles de agarosa al 1.5\% elaborados con buffer TAE $1 \mathrm{X}$ y bromuro de etidio $(0.5 \mu \mathrm{g} / \mathrm{ml})$. La electroforesis se llevó a cabo durante 3 horas a 110 voltios, luego se fotografiaron los geles $(20 \mathrm{x} 10 \mathrm{~cm})$ para la posterior identificación y lectura de los fragmentos polimórficos.

\subsection{Análisis estadístico}

Para el análisis estadístico se utilizó el paquete estadístico NTSYS-pc (Rohlf, 1998), los pares de similitud genética fueron calculados de la matriz de datos binarios. La lectura fue realizada en un sistema binario donde 1 = presencia, 0 = ausencia; los fragmentos que representaron un dato dudoso durante la lectura se nominaron con "9", usando el coeficiente de Jaccard:

$$
\mathrm{F}=\mathrm{Mxy} /(\mathrm{Mt}-\mathrm{Mxyo})
$$

donde $\mathrm{F}$ = coeficiente de Jaccard; Mxy = número de fragmentos compartidos entre dos accesiones; Mt = número total de fragmentos en la matriz de datos; Mxyo = número de fragmentos en la matriz de datos que no fueron evidentes en ninguna de las accesiones.

Se obtuvo el respectivo dendrograma mediante el método de agrupamiento UPGMA (Unweighted Pair Group Method using Arithmetic averages), y el uso de la opción SAHN CLUSTERING del paquete NTSYS. Paralelamente se realizó el análisis de coordenadas principales (PCO) con el cálculo anticipado de los valores eigen, todo esto en el mismo programa estadístico mencionado. Para poder medir el grado de distorsión de los agrupamientos resueltos por el método anteriormente especificado, se empleó el coeficiente cofenético, cuyo valor " $r$ " debe ser igual o mayor a 0.8 para deducir que el método utilizado fue el apropiado (Crisci \& López, 1993).

\section{RESULTADOS}

El protocolo de extracción recomendado por Yaguache \& Medina (2003), resultó eficiente para la extracción de ADN en estas especies. Durante la cuantificación se observó la presencia de fragmentos definidos y las concentraciones obtenidas de acuerdo a la valoración con el estándar Low DNA Mass Ladder fueron de hasta $300 \mathrm{ng} / \mu \mathrm{l}$.

De los 14 iniciadores utilizados se obtuvieron 76 fragmentos polimórficos que mostraron mayor claridad y definición, con un tamaño entre 368 y 2102 pares de bases (pb). La replicabilidad se comprobó repitiendo la amplificación. El menor número de fragmentos fue generado con los iniciadores AA-07 y AN-16, y el mayor número fue amplificado con los iniciadores AA-02, AM-09 y AN-15, con 2 y 8 fragmentos, respectivamente (Tabla 1).

\footnotetext{
${ }^{3} \mathrm{U} / \mu \mathrm{l}$ : una unidad de actividad enzimática/microlitro

${ }^{4}$ pmol: picomole
} 
Tabla 1. Lista de los 14 primers utilizados con sus secuencias y los fragmentos polimórficas amplificados.

\begin{tabular}{cccc}
\hline $\begin{array}{c}\text { Código de } \\
\text { laboratorio }\end{array}$ & $\begin{array}{c}\text { Código } \\
\text { Operon }\end{array}$ & Secuencia 5'-3' & Polimorfismos evaluados (tamaños en pb) \\
\hline 1 & AA-02 & GAGACCAGAC & $1411,1279,1191,1061,992,908,832,659$ \\
2 & AA-04 & AGGACTGCTC & $917,836,762,633$ \\
3 & AA-07 & CTACGCTCAC & 1349,1218 \\
4 & AA-11 & ACCCGACCTG & $1285,991,687$ \\
5 & AA-18 & TGGTCCAGCC & $1607,1228,1144,851,796$ \\
6 & AC-01 & TCCCAGCAGA & $1339,997,941,749,716,573,547$ \\
7 & AC-19 & AGTCCGCCTG & $2102,1822,1497,1286$ \\
8 & AM-04 & GAGGGACCTC & $1330,1165,664,633,576$ \\
10 & AM-07 & AACCGCGGCA & $993,535,595,471,415,365$ \\
11 & AM-09 & TGCCGGTTCA & $1183,1051,851,774,745,678,617,541$ \\
12 & AN-01 & ACTCCACGTC & $967,850,774,667,595,572,509$ \\
13 & AN-15 & TGATGCCGCT & $1359,1163,999,860,458,573,548,388$ \\
14 & AN-16 & GTGTCGAGTC & 1079,560 \\
15 & AN-20 & GAGTCCTCAC & $614,561,536,524,468,415,368$ \\
\hline
\end{tabular}

Las secuencias de cada uno de los iniciadores utilizados en el estudio, los respectivos rangos de amplificación, número de fragmentos obtenidos por iniciador y número y peso de los fragmentos evaluados, se exponen en la Tabla 1. Las frecuencias de las bandas polimórficas evaluadas en los materiales del estudio se encuentran en la Tabla 2. Se aprecia que las bandas más frecuentes son AM$07_{365}$ y AN-15 1163 y las menos frecuentes son AA-04917, AA-18 1144 y AA- 18796 .

Tabla 2. Frecuencias de las bandas polimórficas evaluadas en los materiales estudiados.

\begin{tabular}{|c|c|c|c|c|c|c|c|}
\hline Primer & $\begin{array}{c}\text { Presencias } \\
(\%)\end{array}$ & $\begin{array}{c}\text { Ausencias } \\
(\%)\end{array}$ & $\begin{array}{c}\text { Dudosas } \\
(\%)\end{array}$ & Primer & $\begin{array}{c}\text { Presencias } \\
(\%)\end{array}$ & $\begin{array}{c}\text { Ausencias } \\
(\%)\end{array}$ & $\begin{array}{c}\text { Dudosas } \\
(\%)\end{array}$ \\
\hline$\overline{\mathrm{AA}}-02_{1411}$ & 36 & 60 & 4 & AM-0 $07_{993}$ & 24 & 74 & 3 \\
\hline AA- $02_{1279}$ & 31 & 64 & 5 & AM- $07_{535}$ & 15 & 84 & 1 \\
\hline AA- $022_{1191}$ & 50 & 46 & 4 & AM-07595 & 43 & 58 & 0 \\
\hline AA-0 $2_{1061}$ & 24 & 73 & 4 & AM- $07_{365} *$ & 96 & 4 & 0 \\
\hline AA-02 ${ }_{992}$ & 18 & 79 & 4 & AM- $07_{471}$ & 54 & 46 & 0 \\
\hline AA- 02908 & 10 & 85 & 5 & AM- $07_{415}$ & 80 & 18 & 3 \\
\hline AA- 02832 & 45 & 51 & 4 & AM- $09_{1183}$ & 95 & 5 & 0 \\
\hline AA- 02659 & 6 & 90 & 4 & AM-09 1051 & 49 & 51 & 0 \\
\hline AA- $04_{836}$ & 78 & 20 & 3 & AM- $09_{851}$ & 26 & 74 & 0 \\
\hline AA- $04_{762}$ & 25 & 74 & 1 & AM- $09_{541}$ & 59 & 41 & 0 \\
\hline AA- $04_{633}$ & 58 & 43 & 0 & AM- $09_{678}$ & 86 & 14 & 0 \\
\hline AA- $04_{917} * *$ & 3 & 98 & 0 & AM- $09_{617}$ & 51 & 49 & 0 \\
\hline AA- $07_{1349}$ & 20 & 71 & 9 & AM-09 $9_{774}$ & 56 & 44 & 0 \\
\hline AA- $07_{1218}$ & 53 & 40 & 8 & AM- $09_{745}$ & 44 & 56 & 0 \\
\hline AA-1 $1_{991}$ & 29 & 70 & 1 & AN- $01_{572}$ & 89 & 11 & 0 \\
\hline AA- $11_{687}$ & 69 & 29 & 3 & AN-01 850 & 35 & 65 & 0 \\
\hline AA- $11_{1285}$ & 58 & 43 & 0 & AN-01 967 & 23 & 78 & 0 \\
\hline AA- $18_{1607} * *$ & 3 & 93 & 5 & AN-01 509 & 9 & 91 & 0 \\
\hline AA- $18_{1144}$ & 35 & 60 & 5 & AN-01 595 & 13 & 88 & 0 \\
\hline AA- 18851 & 28 & 68 & 5 & AN-01 667 & 48 & 53 & 0 \\
\hline
\end{tabular}


Tabla 2. (continuación)

\begin{tabular}{|c|c|c|c|c|c|c|c|}
\hline Primer & $\begin{array}{c}\text { Presencias } \\
(\%)\end{array}$ & $\begin{array}{c}\text { Ausencias } \\
(\%)\end{array}$ & $\begin{array}{c}\text { Dudosas } \\
(\%)\end{array}$ & Primer & $\begin{array}{c}\text { Presencias } \\
(\%)\end{array}$ & $\begin{array}{c}\text { Ausencias } \\
(\%)\end{array}$ & $\begin{array}{c}\text { Dudosas } \\
(\%)\end{array}$ \\
\hline AA-18 $1228 * *$ & 3 & 93 & 5 & AN-01774 & 28 & 70 & 3 \\
\hline AA-18796 & 25 & 70 & 5 & $\mathrm{AN}-15_{1359}$ & 16 & 84 & 0 \\
\hline AC- $-01_{1339}$ & 19 & 80 & 1 & AN-15 $1163 *$ & 98 & 3 & 0 \\
\hline AC- $01_{941}$ & 16 & 83 & 1 & AN-15999 & 78 & 21 & 1 \\
\hline AC- $01_{749}$ & 6 & 91 & 3 & $\mathrm{AN}-15_{458}$ & 71 & 24 & 5 \\
\hline AC- $01_{716}$ & 74 & 25 & 1 & AN-15388 & 89 & 10 & 1 \\
\hline AC- $-01_{573}$ & 85 & 15 & 0 & AN- 15573 & 59 & 36 & 5 \\
\hline $\mathrm{AC}-01_{547}$ & 33 & 66 & 1 & AN- $15_{548}$ & 36 & 63 & 1 \\
\hline AC-01 997 & 95 & 5 & 0 & $\mathrm{AN}-15_{860}$ & 41 & 55 & 4 \\
\hline $\mathrm{AC}-19_{2102}$ & 24 & 75 & 1 & $\mathrm{AN}-16_{1079}$ & 53 & 45 & 3 \\
\hline AC- $19_{1822}$ & 6 & 93 & 1 & AN-16 560 & 10 & 90 & 0 \\
\hline AC-19 1497 & 44 & 51 & 5 & AN-20 614 & 89 & 11 & 0 \\
\hline AC- $19_{1286}$ & 29 & 70 & 1 & AN-20 561 & 8 & 93 & 0 \\
\hline AM- $04_{1165}$ & 8 & 93 & 0 & AN-20 536 & 9 & 91 & 0 \\
\hline AM-04664 & 66 & 34 & 0 & AN-20 415 & 89 & 11 & 0 \\
\hline AM-04 633 & 91 & 9 & 0 & $\mathrm{AN}-20_{368}$ & 90 & 10 & 0 \\
\hline $\mathrm{AM}-04_{576}$ & 86 & 13 & 1 & AN-20 478 & 11 & 89 & 0 \\
\hline AM- $04_{1330}$ & 73 & 26 & 1 & AN-20 524 & 18 & 83 & 0 \\
\hline
\end{tabular}

* Fragmentos polimórficos con el porcentaje más alto de presencias

** Fragmentos polimórficas con porcentajes más altos de ausencias

En la Figura 1 se muestran las frecuencias de los 76 fragmentos polimórficos evaluados, se puede advertir que existen 21 de ellos con menos del $20 \%$ de frecuencias, es decir, que son raros en el grupo, pudiendo constituirse en fragmentos de interés y que podrían dar alguna característica especial en los materiales que los poseen.

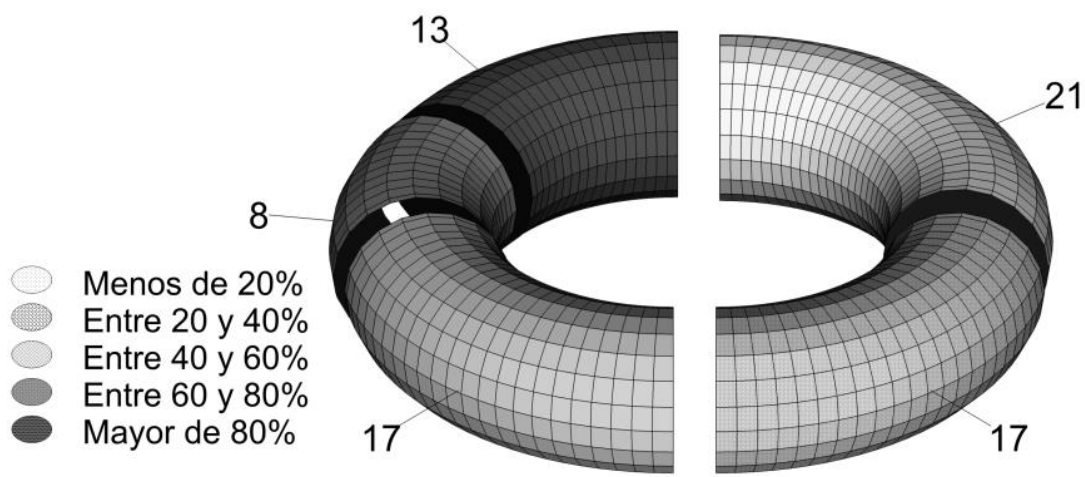

Figura 1. Frecuencias de los 76 fragmentos polimórficos evaluados en los materiales en estudio.

En la Tabla 3 se presenta los porcentajes de los fragmentos polimórficos que registraron menor frecuencia en cada género y especie, destacándose AA-04 ${ }_{917}$, AA-18 ${ }_{1607}$ y AA-18 ${ }_{1228}$, encontrados solamente en las accesiones del género Carica; AA-02 659 está presente solamente en las $V$. candicans y $V$. parviflora; y AM-04 ${ }_{1165}$ en V. omnilingua y C. papaya.

La matriz generada por los datos moleculares, utilizando el coeficiente de Jaccard, indica los coeficientes de similitud obtenidos entre pares de accesiones. Además, se puede observar que el valor medio de similitud obtenido en todo el grupo de materiales estudiados es igual a 0.47. En cuanto al 
análisis estadístico, en la Figura 2, se puede observar el dendrograma obtenido a partir de la matriz de similitud, el valor cofenético aplicado en dicha figura fue igual a 0.82, según Crisci \& López (1983) esto indica una baja distorsión en la formación de los grupos. En la mencionada figura, un corte realizado a 0.36 de similitud nos permite observar la separación de 4 grupos (A, B, C y D): el grupo A, que integra exclusivamente materiales de la llamada especie Vasconcellea candicans y corresponden a materiales procedentes de provincia de Loja; el grupo B, que aglomera al resto de Vasconcelleas del estudio; el grupo C, que agrupa a los dos únicos materiales del género Jacaratia, que fueron colectados en la provincia de Zamora Chinchipe; y finalmente el grupo D, que incluye a los materiales de Carica papaya pertenecientes a la provincia del Azuay. Todos estos grupos comparten niveles de similitud bajos y esto divide a los distintos géneros del estudio, excepto los materiales del grupo A con respecto a los del B, lo cual indica que comparten muy poca información desde el punto de vista molecular.

Tabla 3. Distribución de los fragmentos menos frecuentes en todas las especies evaluadas.

\begin{tabular}{|c|c|c|c|c|c|c|c|c|c|c|c|c|c|c|c|c|c|c|c|c|c|}
\hline \multirow[b]{2}{*}{$\begin{array}{l}\text { Género o } \\
\text { especie }\end{array}$} & \multicolumn{21}{|c|}{ Porcentajes respecto al total de presencias } \\
\hline & 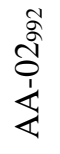 & 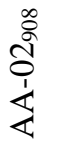 & 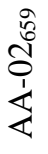 & 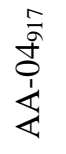 & $\begin{array}{l}\text { 勇 } \\
\frac{1}{0} \\
\frac{1}{<}\end{array}$ & $\frac{\stackrel{0}{0}}{\frac{0}{\infty}}$ & $\frac{\stackrel{\infty}{\mathbb{N}}}{\frac{\infty}{\dot{\infty}}}$ & 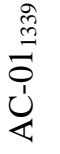 & 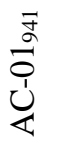 & 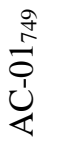 & 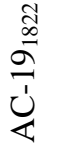 & $\begin{array}{l}\stackrel{n}{=} \\
\underset{J}{ \pm} \\
\sum_{d}^{1}\end{array}$ & 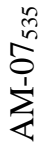 & $\begin{array}{l}\stackrel{8}{6} \\
\stackrel{6}{0} \\
\dot{1} \\
z \\
\end{array}$ & $\begin{array}{l}\text { an } \\
\vdots \\
0 \\
z \\
z\end{array}$ & $\frac{\stackrel{b}{n}}{\frac{n}{2}}$ & $\frac{8}{0}$ & 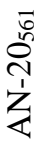 & 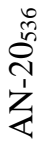 & $\begin{array}{l}\stackrel{\infty}{+} \\
\stackrel{\overbrace{}}{+} \\
\stackrel{1}{Z}\end{array}$ & 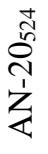 \\
\hline VCAN & 0 & 0 & 80 & 0 & 13 & 0 & 0 & 13 & 8 & 20 & 0 & 0 & 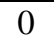 & 0 & 10 & 31 & 0 & 33 & 29 & 22 & 0 \\
\hline VCUN & 7 & 0 & 0 & 0 & 31 & 0 & 0 & 0 & 0 & 20 & 0 & 0 & 0 & 0 & 0 & 0 & 0 & 0 & 14 & 0 & 14 \\
\hline VHEI & 36 & 13 & 0 & 0 & 19 & 0 & 0 & 33 & 8 & 20 & 0 & 0 & 8 & 71 & 10 & 15 & 0 & 0 & 0 & 11 & 21 \\
\hline VLON & 0 & 0 & 0 & 0 & 0 & 0 & 0 & 0 & 0 & 0 & 20 & 0 & 0 & 0 & 0 & 0 & 0 & 0 & 0 & 0 & 0 \\
\hline VMIC & 0 & 25 & 0 & 0 & 0 & 0 & 0 & 7 & 0 & 0 & 0 & 0 & 0 & 14 & 0 & 8 & 0 & 0 & 14 & 0 & 7 \\
\hline VMON & 7 & 0 & 0 & 0 & 0 & 0 & 0 & 0 & 0 & 0 & 20 & 0 & 0 & 0 & 0 & 0 & 0 & 0 & 0 & 0 & 0 \\
\hline VOMN & 0 & 0 & 0 & 0 & 0 & 0 & 0 & 13 & 15 & 0 & 20 & 83 & 0 & 0 & 10 & 0 & 0 & 50 & 29 & 22 & 7 \\
\hline VPAL & 0 & 0 & 0 & 0 & 6 & 0 & 0 & 0 & 0 & 0 & 0 & 0 & 0 & 0 & 0 & 0 & 0 & 0 & 0 & 0 & 0 \\
\hline VPAR & 36 & 0 & 20 & 0 & 0 & 0 & 0 & 0 & 23 & 0 & 0 & 0 & 25 & 0 & 20 & 0 & 25 & 0 & 0 & 11 & 0 \\
\hline VSP & 7 & 38 & 0 & 0 & 31 & 0 & 0 & 13 & 38 & 0 & 40 & 0 & 17 & 0 & 30 & 8 & 25 & 17 & 0 & 22 & 21 \\
\hline VSTP & 7 & 25 & 0 & 0 & 0 & 0 & 0 & 13 & 8 & 40 & 0 & 0 & 33 & 14 & 10 & 31 & 50 & 0 & 14 & 0 & 21 \\
\hline CPAP & 0 & 0 & 0 & 100 & 0 & 100 & 100 & 7 & 0 & 0 & 0 & 17 & 8 & 0 & 10 & 8 & 0 & 0 & 0 & 11 & 7 \\
\hline JAC & 0 & 0 & 0 & 0 & 0 & 0 & 0 & 0 & 0 & 0 & 0 & 0 & 8 & 0 & 0 & 0 & 0 & 0 & 0 & 0 & 0 \\
\hline NBP & 14 & 8 & 5 & 2 & 16 & 2 & 2 & 15 & 13 & 5 & 5 & 6 & 12 & 7 & 10 & 13 & 8 & 6 & 7 & 9 & 14 \\
\hline$\% \mathrm{BPT}$ & 18 & 10 & 6 & 3 & 20 & 3 & 3 & 19 & 16 & 6 & 6 & 8 & 15 & 9 & 13 & 16 & 10 & 8 & 9 & 11 & 18 \\
\hline
\end{tabular}

NBP: número de presencias por bandas polimórfica

$\%$ BPT: porcentaje de presencias con respecto al total (Tabla 2)

Los datos en color rojo significan la presencia de ciertas bandas de ADN solo en algunas accesiones

Como se expuso anteriormente, el grupo B lo conforman materiales del género Vasconcellea, y dentro de este se puede advertir la integración de 12 Subgrupos, cada uno de ellos formados por materiales de las mismas especies, manteniendo entre ellos distintos niveles de similitud. Así el Subgrupo B1, que representa los materiales de la especie $V$. stipulata que han sido colectados en las provincias de Azuay y Loja, se une a un nivel de similitud de 0.52 con el B2 que está formado por materiales de los notomorfos pentágona y chrysopetala del híbrido natural denominado $V$. x heilbornii, todos ellos oriundos de la provincia del Azuay. Luego, en el nivel 0.46 de similitud, los materiales de la especie $V$. parviflora (procedentes de la provincia de Loja) conglomerados en el subgrupo B3, se unen con los fusionados Subgrupos B1 y B2. Por su parte, el Subgrupo B4 está integrado por materiales de $V$. sp. (colectados en las provincias del Azuay y Cañar), nombrados de esta forma ya que constituyen materiales que no se pueden ubicar en otra especie por diferir morfológicamente a las ya reconocidas. Así, se puede recordar que todas las $V$. $s p$. Comparten características morfológicas con $V$. cundinamarcensis pero que a la vez difieren con estar separada de $V$. cundinamarcensis (procedentes 


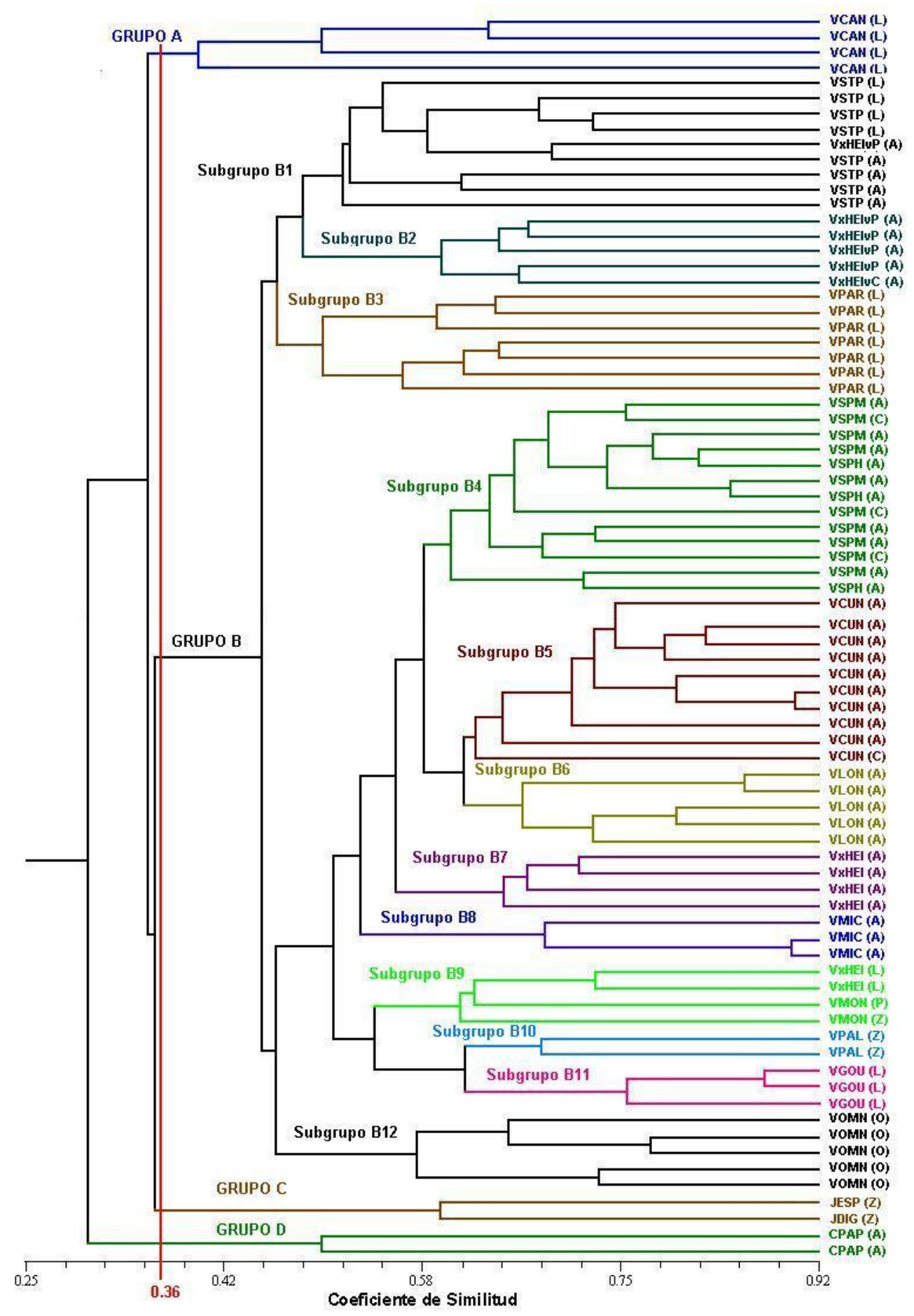

Figura 2. Dendrograma obtenido a partir de 76 bandas RAPD polimórficas evaluadas en los 78 materiales en estudio y correspondientes a los grupos: A (Azuay); B (Azuay, Cañar, El Oro, Loja, Pastaza, Zamora Chinchipe); C (Zamora Chinchipe); y D (Azuay). Se ha realizado una línea de corte a 0.36 de similitud.

del Azuay y Cañar) cuyos materiales se encuentran en el Subgrupo B5 que a la vez está más cerca de las V. longiflora (colectadas en el Azuay) que constituye a B6, a un nivel de similitud igual a 0.63, para luego unirse a los materiales de V. sp. a 0.58 de similitud. El resultado de la unión de los Subgrupos B5 y B6 con el B4, se liga luego en 0.53 de similitud al Subgrupo B7, formado por otros materiales del denominado híbrido natural V. x heilbornii, pero esta vez corresponden a notomorfos desconocidos y que han sido colectados en la Provincia del Azuay. Esta nueva unión, a un nivel de 0.53 de similitud, se 
une con el Subgrupo B8 que corresponde a los materiales de la especie V. microcarpa procedentes de la Provincia del Azuay.

El Subgrupo B11 que corresponde a V. goudotiana (todas ellas de la provincia de Loja) se fusiona con el B10 que agrupa a materiales de V. palandensis, colectados en Zamora Chinchipe, en 0.63 de similitud. El Subgrupo B9 incluye materiales de la especie V. monoica (de las provincias de Pastaza y Zamora Chinchipe) y el híbrido natural V. x heilbornii procedente de Loja, los cuales mantienen entre ellos un nivel de similitud de 0.63. Seguidamente el Subgrupo B9 se une al B11 y B10 en 0.54 de similitud. En un nivel un poco más bajo de similitud (0.50), se une el conglomerado formado por los Subgrupos B4, B5, B6, B7 y B8 con el integrado por los Subgrupos B9, B10 y B11. El resultado de este último, y en un nivel de similitud correspondiente a 0.46, se fusiona con el Subgrupo B12 de materiales de la especie V. omnilingua, las cuales se las ha colectado en la provincia de El Oro. Por último, la agrupación formada por los Subgrupos B1, B2 y B3 se une con la otra agrupación que constituyen todos los Subgrupos de B4 a B12, en un nivel de similitud igual a 0.45.

\section{DISCUSIÓN}

El dendrograma de la Figura 2 indica la formación de cuatro grupos de los cuales el D es el más distante, con 0.30 de similitud, y que aglomera a materiales del género Carica, coincidiendo con el estudio realizado por Van Droogenbroeck et al. (2002); Kyndt et al. (2005a) en donde se analiza mediante AFLP (amplified fragment length polymorphism) las relaciones genéticas dentro y entre los géneros Carica y Vasconcellea, proveyendo un fuerte soporte para considerar a Vasconcellea en un solo género; resultados presentados por Van Droogenbroeck et al. (2004) usando PCR-RFLP sugieren la existencia de dos linajes dentro de las Caricaceae, la primera comprende solamente a Vasconcellea spp., y el segundo grupo contiene el resto de las especies de Vasconcellea, junto con genotipos de Carica, Cylicomorpha y Jacaratia. Esta subdivisión en dos linajes contrasta con los resultados publicados por Aradhya et al. (1999) y con los nuestros, sin embargo, el agrupamiento observado en este estudio puede servir como base para trabajos de fitomejoramiento. Se observa además a las V. candicans (Anexo 1) en un nivel de 0.34 de similitud, lo cual muestra una gran distancia genética de los materiales pertenecientes a este género con respecto al resto de materiales de los grupos $\mathrm{B}$ y $\mathrm{C}$, lo cual se evidencia también a través de las distintas características morfológicas existentes entre las mencionadas especies y el resto de Vasconcelleas. Sin embargo, el resultado obtenido por Yaguache \& Medina (2003) concuerda con lo observado en el presente estudio, aunque Van Droogenbroeck et al. (2002) indican en su trabajo un grado de similitud genética mayor, la distancia es considerable.

El grupo C de las Jacaratia mantiene un nivel de similitud igual a 0.35 considerándolo bajo y coincidiendo además con el resultado obtenido por Van Droogenbroeck et al. (2002) en su estudio, donde observa una baja similitud (menor a 0.30) entre las Jacaratias y las Vasconcelleas.

En el grupo B, que integra al resto de Vasconcelleas, se puede apreciar que la similitud está en un promedio de 0.45. Dentro de este se observa la formación de 12 Subgrupos y las interrelaciones genéticas existentes que a la vez coinciden, en algunos casos, con otros estudios realizados en las mismas especies. Cada uno de los Subgrupos está conformado por materiales, en su mayoría de la misma especie. Cabe mencionar la separación de los materiales del híbrido natural $V . x$ heilbornii en tres Subgrupos distintos B2, B7 y B9, similar resultado observó Van Droogenbroeck et al. (2002) en su estudio ya mencionado, pero en este caso se ubicaban solamente en dos grupos distintos.

Según Tina Kyndt (comunicación personal) se han encontrado muchas $V$. $x$ heilbornii que están más relacionadas con $V$. stipulata; sin embargo, existe un pequeño grupo de $V$. x heilbornii que presentan pubescencia y una relación genética con $V$. cundinamarcensis. Kyndt et al. (2005b) reportaron resultados del análisis de secuencias de la región ITS $^{5}$ nuclear confirmando la presencia de dos linajes: el primero integra a $V$. x heilbornii, $V$. weberbaueri, $V$. stipulata and $V$. parviflora; las relaciones y evolución de estos taxones mostraron una estrecha relación fenética reportados por análisis moleculares (Van Droogenbroeck et al., 2002, 2004; Kyndt et al., 2005a). El segundo linaje integra a todos los otros

\footnotetext{
${ }^{5}$ ITS: Internal Transcriptional Sequence
} 
taxones dentro de Vasconcellea, sin embargo, notablemente el árbol filogenético ITS excluye de este clado a $V$. quercifolia, $V$. chilensis, $V$. candicans y $V$. crassipetala y pone estos cuatro taxones en la base de Vasconcellea.

Así, se puede apreciar la cercanía de los materiales de $V$. x heilbornii var. pentagona y chrysopetala (Subgrupo B2) con las V. stipulata (Subgrupo B1) y luego éstas se relacionan genéticamente con las $V$. parviflora (Subgrupo B3), al igual que lo obtenido por Van Droogenbroeck et al. (2002, 2004), donde se presentan las mismas relaciones, pero con diferentes niveles de similitud, lo cual puede ser atribuible a la distinta técnica molecular utilizada.

El segundo Subgrupo B7 corresponde a las $V$. $x$ heilbornii que están más cercanas a la $V$. cundinamarcensis corroborando una vez más lo expuesto por Van Droogenbroeck et al. (2002) y Kyndt (2005a, 2005b); sin embargo, Van Droogenbroeck et al. (2006) encontraron pruebas de hibridación contemporánea entre $V$. stipulata, $V$. cundinamarcensis y $V$. x heilbornii en el Sur del Ecuador.

El tercer Subgrupo B9 corresponde a las $V$. x heilbornii, las cuales están más relacionadas con las $V$. monoica, dicho caso puede ser explicado por la forma del fruto y el peculiar comportamiento que comparten los dos materiales del mencionado Subgrupo, que consiste en la persistencia del fruto en la planta aún después de haber madurado. Además, se pudo observar un resultado similar en un estudio realizado por Yaguache \& Medina (2003) en donde se analiza mediante RAPD distintos genotipos de Vasconcelleas del Sur del Ecuador.

El análisis rápido de las características morfológicas, fenológicas y los datos moleculares obtenidos sugieren la posible existencia de un híbrido natural entre $V$. monoica y $V$. x heilbornii, el cual fue colectado en Loja y se encontraba conservado en la colección viva del proyecto INIAP-PROMSA, ubicada en la Estación Experimental Chuquipata, Granja Experimental Bullcay de INIAP pero que lamentablemente se ha perdido como para proseguir con estudios que confirmen esta presunción y que aporten mayores conocimientos (Anexo 2). En varios reportes realizados por Kyndt et al. (2005a) y Van Droogenbroeck et al. (2002, 2004, 2006), usando otras técnicas como AFLP, PCR-RFLP de ADN mitocondrial y cloroplastos, se indica un alto grado de diversidad genética en $V$. $x$ heilbornii, probablemente resultado de varios eventos de hibridación (múltiples orígenes) y segregación después de la reproducción sexual.

Vasconcellea sp. (Subgrupo B4) es una planta silvestre registrada durante el estudio "Diversidad de Frutales Nativos Comestibles Caricaceae-Solanaceae, Fenología, Usos y Recolección de Germoplasma en el Sur del Ecuador". Según Criollo (2003), comparte características morfológicas con $V$. cundinamarcensis, pero a la vez presenta algunas diferencias en lo referente al fruto y pubescencia (Anexo 3), que son características que no concuerdan con las ya establecidas por Badillo et al. (2000) para las especies de Vasconcelleas presentes en el Sur del Ecuador. Además, se la encuentra únicamente en las estribaciones de la cordillera occidental, entre las provincias del Azuay y Cañar y sin haberse registrado hasta el momento en otras localidades. Finalmente, sugiere que este grupo podría tratarse de un nuevo registro para la parte Austral del Ecuador, ya que Badillo (2000) no reporta una especie con estas características en la zona. En el presente estudio, se puede observar en el dendrograma obtenido, que efectivamente existe una relación directa entre $V$. sp. (Subgrupo B4) y V. cundinamarcensis (Subgrupo B5), pero a la vez se encuentran claramente definidos en dos grupos distintos en un nivel de similitud de 0.58. Por lo tanto, se puede sugerir que los materiales de este Subgrupo B4 corresponden por lo menos a otra variedad de la especie $V$. cundinamarcensis, sin embargo, esto podría ser objeto de estudios más profundos que permitan confirmarlo. Van Droogenbroeck et al. $(2004,2006)$ sugieren que, así como $V$. $x$ heilbornii, otras especies podrían originarse por hibridación ínterespecífica.

Se puede advertir la cercanía de las $V$. longiflora (Subgrupo B6) con las $V$. cundinamarcensis (Subgrupo B5) en 0.63 de coeficiente de similitud. Cabe indicar que no se ha incluido en trabajos anteriores a las V. longiflora junto con Vasconcelleas del Sur del Ecuador, por considerarlas propias de Colombia, sin haber sido registradas en el Ecuador hasta la realización de las colectas por parte de los proyectos financiados por PROMSA y ejecutados por las instituciones INIAP-UDA (Universidad del Azuay) y Fundación San Francisco-UTPL (Universidad Técnica Particular de Loja). La cercanía de los Subgrupos B10 (V. palandensis) y B11 (V. goudotiana, nuevo registro para Ecuador), se apoya también en algunas características morfológicas destacables que comparten como la forma de los frutos (Anexo 4). El dendrograma muestra un valor de 0.63 de similitud genética. 
En los trabajos de Van Droogenbroeck et al. $(2002,2004)$ se incluyeron dos grupos de materiales no identificados que habían sido colectados de las localidades Vilcabamba (Yambala) y Palanda, denominándolos como carv y carp respectivamente. Las relaciones de similitud genética obtenidas de ellos para con las $V$. palandensis fueron de alrededor de 0.58 . Los autores de los mencionados estudios concluyeron además que este grupo de accesiones (especialmente de las carv) comparten mucha similitud morfológica con las $V$. palandensis, pero sus resultados moleculares indican que son distintos. Finalmente sugieren que nuevas colectas deben ser realizadas y analizadas para determinar si esos grupos (carv y carp) representan otra nueva especie. En análisis anteriores de AFLP (Van Droogenbroeck et al., 2002, 2004), V. monoica y V. palandensis, confirman su estrecha relación genética.

Kyndt (2005a, 2005b) han confirmado que los materiales carv del estudio de Van Droogenbroeck et al. (2002) corresponden a los que integran el Subgrupo B11 en el dendrograma de la Figura 2, ya que provienen de los mismos sitios de colecta y han sido identificados por ellos tanto morfológica como molecularmente con $V$. goudotiana. Por otra parte, Romero (2004), en comunicación personal, confirma que estos materiales constituyen el primer registro de $V$. goudotiana en el país, descartando así la sugerencia de que se trate de un nuevo taxón para el Ecuador. Mientras que los materiales de carp no han sido identificados aún y probablemente se trate de híbridos espontáneos entre especies compatibles (Kyndt, 2005b).

Finalmente, el último Subgrupo B12, que corresponde a la $V$. omnilingua, se encuentra a un coeficiente de similitud igual a 0.46 con otros Subgrupos de Vasconcellea (Figura 2).

\section{CONCLUSIONES Y RECOMENDACIONES}

La técnica RAPD permitió discriminar grupos, los resultados guardan concordancia con otros trabajos similares en los que incluso se han usado técnicas más sensibles como AFLP, PCR-RFLP. En este sentido, RAPD es recomendable para este tipo de estudios, sobre todo para nuestro medio, ya que es una técnica simple, relativamente económica y no requiere conocimiento previo sobre la secuencia del ADN del genoma. La caracterización morfo-agronómica es una forma factible de estimar la diversidad genética y esencial para discriminación de los genotipos, sin embargo, la mayor limitación de esta técnica se presenta cuando existen rasgos que podrían ser influenciados por el ambiente o rasgos de herencia poligénica. Para solucionar este problema el uso de técnicas moleculares a nivel de ADN permite detectar la variación directamente y evaluar la relación entre los genotipos, pudiendo ser los RAPD una alternativa viable. Sin embargo, técnicas que usan marcadores dominantes como RAPD y AFLP no son siempre exitosas para la identificación e híbridos o estimaciones intraespecíficas de parámetros genéticos en poblaciones.

El dendrograma obtenido mostró agrupamientos claramente definidos por especie (Figura 2), y en éste, se pudo confirmar las relaciones genéticas existentes entre las distintas especies, coincidiendo muchas de ellas, con otros estudios publicados. La especie silvestre ( $V$. $s p$.) presenta un agrupamiento claro y definido, bastante cercano a $V$. cundinamarcensis. Este trabajo apoya la hipótesis de nominarla como un nuevo taxón, expresada por Criollo (2003). Sin embargo, esta conclusión debe ser reforzada aún más con estudios y análisis.

Los resultados del presente estudio no confirman a la especie silvestre $V$. $s p$. como un híbrido, dado que todos estos materiales se conglomeraron dentro de un mismo grupo. El género Carica se presentó como un grupo distinto, es decir, comparte un menor grado de similitud con el resto de materiales. De igual forma, las $V$. candicans se ubican con bajos niveles de similitud respecto al resto de Vasconcelleas, por lo que su inclusión dentro del género actual debería revisarse. El grupo de las Vasconcelleas, excepto $V$. candicans, mantiene un mayor nivel de similitud (0.45) y está formado por 12 Subgrupos (Figura 2) cuyas interrelaciones genéticas son muy parecidas a resultados obtenidos en trabajos anteriores. Existen tres Subgrupos B2, B7 y B9 de V. x heilbornii que se encuentran distantes entre sí, lo cual indica, que parece ser un grupo de fácil hibridación. Así, existe uno que comparte diversas características moleculares con $V$. stipulata, otro grupo con $V$. cundinamarcensis, y el último está asociado con materiales de $V$. monoica. 


\section{BIBLIOGRAFÍA}

Aradhya MK, Manshardt RM, Zee F, Morden CW (1999). A phylogenetic analysis of the genus Carica L. (Caricaceae) based on restriction fragment length variation in a cpDNA intergenic spacer region. Genetic Resources and Crop Evolution 46, 579-586

Badillo VM (1971). Monografía de la Familia Caricaceae. Maracay, Venezuela: Publicada por la Asociación de Profesores, Facultad de Agronomía, Universidad Central de Venezuela, pp. 7-11

Badillo VM (1993). Caricaceae: segundo esquema. Revista de la Facultad de Agronomía de la Universidad Central de Venezuela 43:1-111

Badillo VM (1997). Neotipificación de Carica pubescens Lenné et Koch y de Carica quercifolia (St. Hil) Hieron. y nuevos registros de la familia para Ecuador. Ernstia 6:201-205

Badillo VM (2000). Carica L. vs Vasconcellea St. Hil. (Caricaceae), con la rehabilitación de este último. Ernstia 10:74-79

Badilo VM, Van den Eynden V, Van Damme P (2000). Carica palandensis (Caricaceae), a new species from Ecuador. Novon 10(1):4-6

Claros MG (2002). Marcardores moleculares: Qué son, cómo se obtienen y para qué valen. Disponible en http://www.encuentros.uma.es/encuentros49/marcadores.html

Carrasco B, Avila P, Perez-Diaz J, Muñoz P, García R, Lavandero B, Zuritasilva A, Retamales JB, Caligari PDS (2009). Genetic structure of highland papayas (Vasconcellea pubescens (Lenné et C Koch) Badillo) cultivated along a geographic gradient in Chile as revealed by Inter Simple Sequence Repeats (ISSR). Genetic Resources and Crop Evolution 56:331-337

Criollo S (2003). Caracterización morfológica y colección de Vasconcellea x heilbornii (Heilborn), Vasconcellea stipulata (VM Badillo) y Vasconcellea cundinamarcensis (VM Badillo) en las provincias de Azuay, Cañar y Loja. Universidad del Azuay, Facultad de Ciencia y Tecnología, Escuela de Biología del Medio Ambiente. Tesis Blga., Cuenca, Ecuador, 37 pp

Crisci J, López M (1983). Introducción a la teoría y práctica de la taxonomía numérica. Facultad de Ciencias Naturales, Universidad Nacional de La Plata. La Plata, Argentina, pp. 39-81

Costa R, Pereira G, Garrido I, Tavares-de-Sousa MM, Espinoza F (2016). Comparison of RAPD, ISSR, and AFLP molecular markers to reveal and classify orchard grass (Dactylis glomerata L.) Germplasm Variations. PLoS One 11(4): e0152972. https://doi.org/10.1371/ journal.pone. 0152972

Estrella J, Phillips S, Abbott RJ, Gillies A, Sørensen M (1998). Genetic variation and relationships in agronomically important species of Yam Bean (Pachyrhizus DC.) on RAPD markers. En: Sørensen M, Estrella E, Hamann JE, Ríos Ruíz SA (Eds.). Proceedings of $2^{\text {nd }}$ International Symposium on Tuberous Legumes, Celaya, Gto., Mexico 5-8 August 1996. København: MacKenzie, pp. 43-60

Ferreira ME, Grattapaglia D (1998). Introducción al uso de marcadores moleculares en el análisis genético (1 ed.). Brasilia, Brasil: EMBRAPA-CENARGEN, 220 pp

Horovitz S, Jiménez H (1976). Cruzamientos interespecíficos e intergenéricos en Caricaceaes y sus implicaciones fitotécnicas. Agronomía Tropical 17:323-344.

INIAP (2003). Informe annual del Proyecto PROMSA "Diversidad de frutales nativos comestibles Garicaceae-Solanaceae, fenología, usos y recolección de germoplasma en el sur del Ecuador". Programa de Fruticultural. EECH, Cuenca, Ecuador

IUCN (2003). The IUCN red list of threatened species. Gland, Switzerland and Cambridge, UK: IUCN Species Survival Commission. Available at website, http://www.iucnredlist.org/

Jiménez Y, Romero J, Scheldeman X (1999). Colección, caracterización y descripción de Carica $x$ heilbornii nm. pentágona B.; Carica pubescens (A. DC.) Solms-Laub y Carica stipulata B., en la provincia de Loja. Revista de Difusión Técnica y Científica (Facultad de Ciencias Agrícolas de la Universidad Nacional de Loja) 29:43-54 
Jhingan AK (1992). A novel technology for DNA isolation. Methods Molecular Cell Biology 3(1):15-22

Kyndt T, Romeijn-Peeters E, Van Droogenbroeck BV, Romero-Motochi JP, Gheysen G, Goetghebeur P (2005a). Species relationships in the genus Vasconcellea (Caricaceae) based on molecular and morphological evidence. American Journal of Botany 92(6):1033-1044

Kyndt T, Van Droogenbroeck BV, Romeijn-Peeters E, Romero- Motochi JP, Scheldeman X, Goetghebeur P, Van Damme P, Gheysen G (2005b). Molecular phylogeny and evolution of Caricaceae based on rDNA Internal Transcribed Spacer (ITS) and chloroplast sequence data. Molecular Phylogenetics and Evolution 37(2):442-459

Morillo E (2000). Protocolos del Laboratorio de Marcadores Moleculares. Instituto Nacional Autónomo de Investigaciones Agropecuarias (INIAP), Departamento Nacional de Recursos Fitogenéticos y Biotecnología (DENAREF). Quito, Ecuador

Morillo E, Miño G (2011). Marcadores moleculares en biotecnología agrícola: Manual de técnicas y procedimientos en INIAP. Instituto Nacional Autónomo de Investigaciones Agropecuarias (INIAP), Quito, Ecuador, 132 pp

National Research Council (1989). Highland papayas. In: Ruskin FR (Ed.). Lost crops of the Incas: Little-Known plants of the Andes with promise for worldwide cultivation. Washington D.C.: National Academy Press, pp 252-261

Oleas N, Meerow A, Ortega F. (2013) Molecular Markers and Conservation of Plant Species in the Latin-America: The Case of Phaedranassa viridiflora (Amaryllidaceae). The Botanical Review 79(4):507-527

Olson, M.E., 2002. Intergeneric relationships within the Caricaceae-Moringaceae clade (Brassicales) and potential morphological synapomorphies of the clade and its families. International Journal of Plant Science 163(1):51-65

Oliveira EJ, Silva AS, Carvalho FM, Santos LF, Costa JL, Amorim VBO, Dantas JLL (2010). Polymorphic microsatellite marker set for Carica papaya $\mathrm{L}$ and its use in molecularassisted selection. Euphytica 173(2):279-287

Oliveira EJ, Costa J, Dos Santos L, Moraes de Carvalho F, Silva A, Loyola JL (2011). Molecular characterization of papaya genotypes using AFLP markers. Revista Brasileira de Fruticultura 33(3):848-858

Peña D (2005). Estudio de la diversidad genética de Caricaceas en el sur del país mediante marcadores RAPD. Tesis de Master en Biotecnología, Programa de Biotecnología, Universidad de Guayaquil, Guayaquil, Ecuador. 68 pp

PROMSA (2003). Diversidad de frutales nativos comestibles Caricaceae y Solanaceae del sur del Ecuador. Proyecto IQCV045: Informe final. Cuenca, Ecuador. $52 \mathrm{pp}$

Ratchadaporn J, Sureeporn K, Khumcha U (2007). An analysis on DNA fingerprints of thirty papaya cultivars (Carica papaya L) grown in Thailand with the use of Amplified Fragment Length Polymorphisms (AFLP) technique. Pakistan Journal of Biological Sciences, Faisalabad 10(18):3072-3078

Rohlf J (1998). Numerical taxonomy and2013 multivariate analysis system NTSYS 2.0. User guide. Department of Ecology and Evolution, State University of New York. New York, USA. 30 pp

Romeijn-Peeters E (2004). Biodiversity of the genus Vasconcellea (Cariucaceae) in Ecuador: a morphological approach. PhD thesis. Faculty of Sciences, Ghent Univerisity, Belgium.

Scheldeman X, Willemen L, Coppens d'Eeckenbrugge G, Romeijn-Peeters E, Restrepo MT, RomeroMotoche J, Jimenez D, Lobo M, Medina CI, Reyes C, Rodriguez D, Ocampo JA, Van Damme P, Goetgebeur P (2007). Distribution, diversity and environmental adaptation of highland papayas (Vasconcellea spp.) in tropical and subtropical America. Biodiversity Conservation Journal 16:18676-1884

Scheldeman X, Kyndt T, Coppens d'Eeckenbrugge GC, Ming R, Drew R, Van Droogenbroeck BV, Van Damme P, Moore PH (2011). Vasconcellea. In: Kole C (Ed.). Wild crop relatives: Genomic 
and breeding resources. Tropical and Subtropical Fruits ( $1^{\text {st }}$ ed.). Berlin Heidelberg: SpringerVerlag

Souza SGH, Carpentieri-Pípolo V, Ruas CF, Carvalho VP, Ruas PM, Geragel AC (2008).

Comparative analysis of genetic diversity among the maize inbred lines (Zea mays L.) obtained by RAPD and SSR markers. Brazilian Archives of Biology and Technoligy 51(1):183-192

Thormann CE, Fereira ME, Camargo LEA, Tivang JG, Osborn TC (1994). Comparison of RFLP and

RAPD markers to estimating genetic relationships within and among cruciferous species.

Theoretical and Applied Genetics 88(8):973-980

Van Droogenbroeck BV, Breyne P, Goetghebeur P, Romeijn-Peeters E, Kyndt T, Gheysen G (2002). AFLP analysis of genetic relationships among papaya and its wild relatives (Caricaceae) from Ecuador. Theorical and Applied Genetics 105(2):289-297

Van Droogenbroeck BV, Kyndt T, Maertens I, Romeijn-Peeters E, Scheldeman X, Romero-Motoche J, Van Damme P, Goetghebeur P, Gheysen G (2004). Phylogenetic analysis of the highland papayas (Vasconcellea) and allied genera (Caricaceae) using PCR-RFLP. Theoretical and Applied Genetics 108(8):1473-1486

Van Droogenbroeck BV, Kyndt T, Maertens I, Romeijn-Peeters E, Van Thuyne W, Goetghebeur P, Romero-Motochi R, Gheysen G (2006). Evidence of natural hybridization and introgression between Vasconcellea species (Caricaceae) from Southern Ecuador revealed by chloroplast, mitochondrial and nuclear DNA markers. Annals of Botany 97(5):793-805

Williams JGK, AR, Livak KJ, Rafalski JA, Tingey SV (1990). DNA polymorphisms amplified by arbitrary primers are useful as genetic markers. Nucleic Acids Research 18(22):6531-6535

Yaguache B, Medina D (2003). Diversidad genética y filogenia de los géneros Carica Vasconcellea del sur del Ecuador. Tesis de grado previa a obtención del título de Ingeniero Agrónomo. Carrera de Ingeniería Agronómica, Universidad Nacional de Loja. Loja, Ecuador. 212 pp 


\section{ANEXO 1}

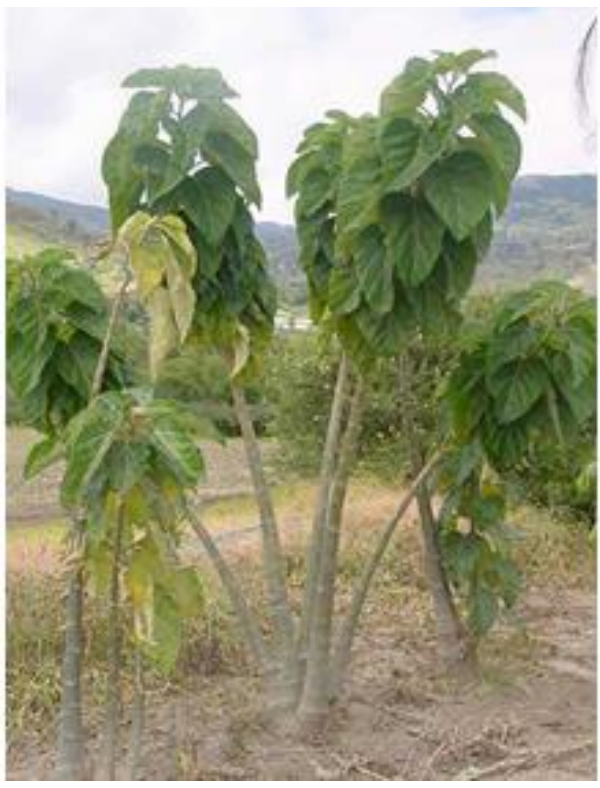

(a)

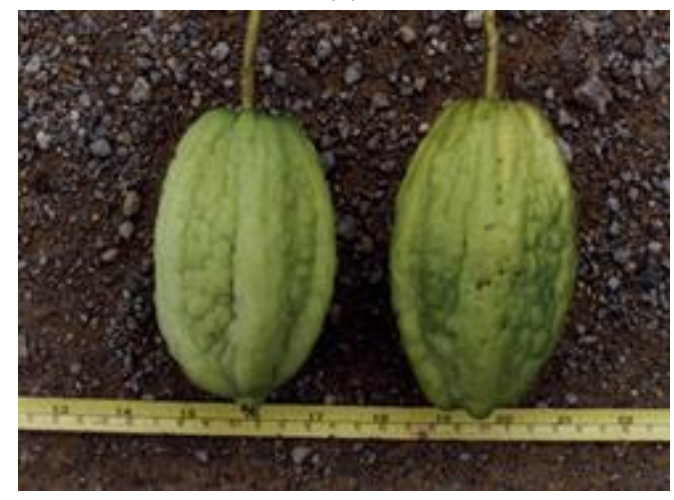

(c)

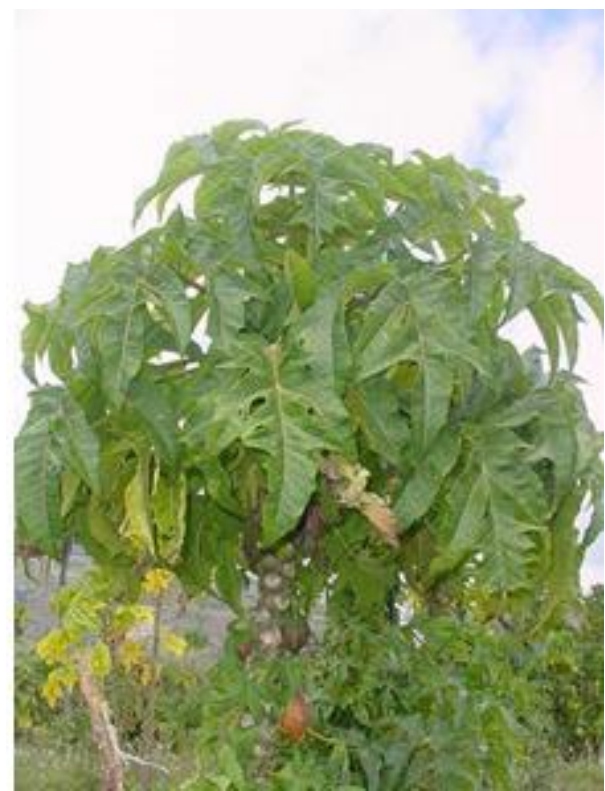

(b)

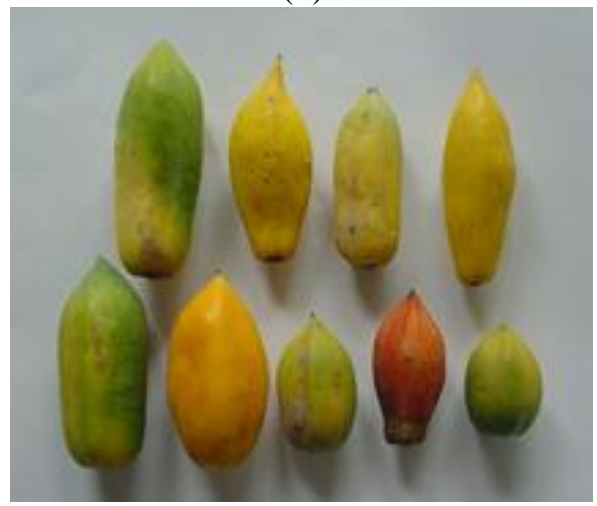

(d)

Fotografías de plantas y frutos pertenecientes a las $V$. candicans (a) y (c), y de una planta y varios frutos representativos del género Vasconcellea (b) y (d), nótese las diferencias en cuanto a la forma de la hoja entera de $V$. candicans comparada con la palmilobulada característica en el resto de Vasconcelleas. 


\section{ANEXO 2}

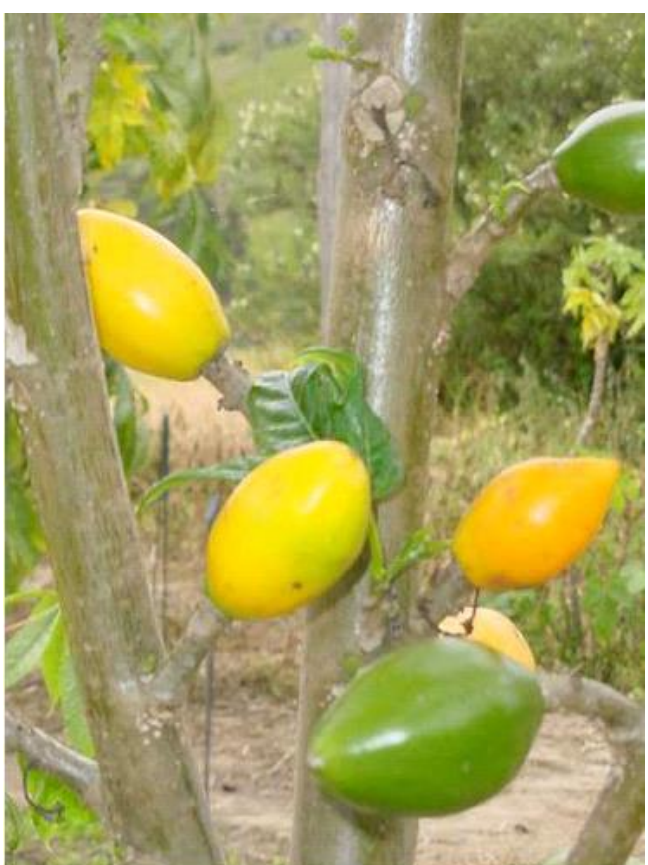

(a)

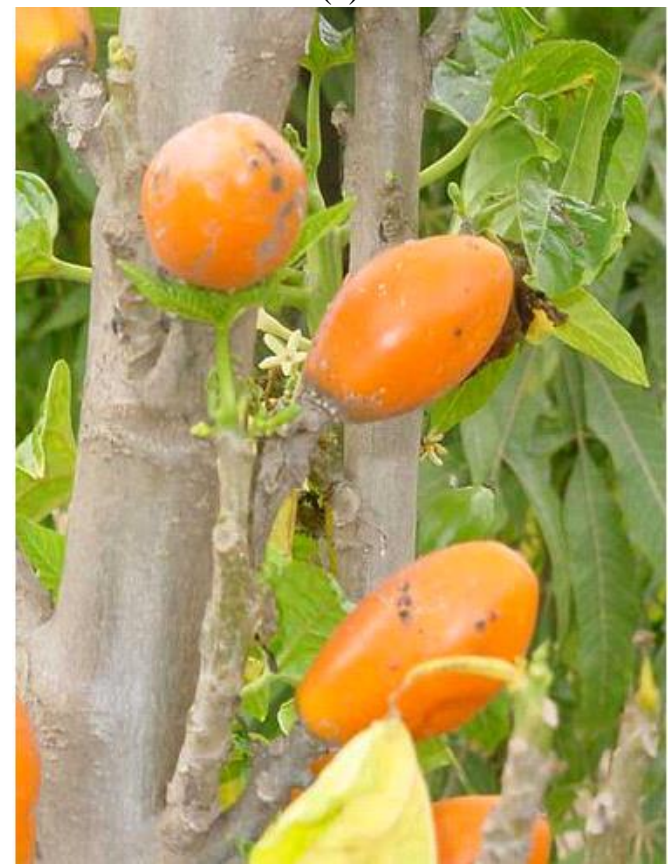

(c)

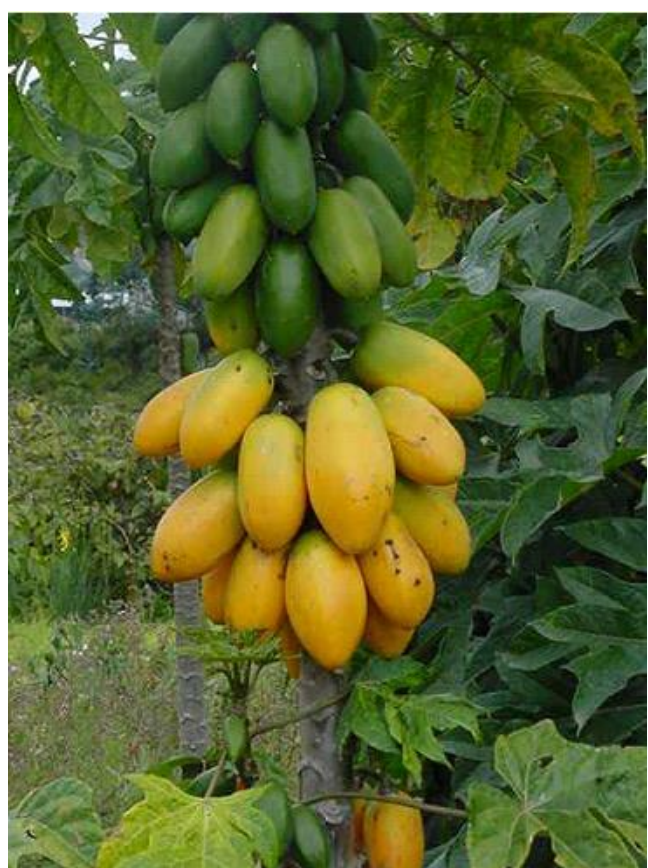

(b)

Fotografías de los materiales pertenecientes al Subgrupo B9 del dendrograma de la Figura 2, (a) y (c) son plantas con los respectivos frutos de las V. monoica, y (b) es una planta de $V$. $x$ heilbornii con los respectivos frutos. Nótese el parecido de los frutos en cuanto a la forma, son brillantes y lisos, además de ello permanecen en la planta por largo tiempo aún después de estar completamente maduras. 


\section{ANEXO 3}

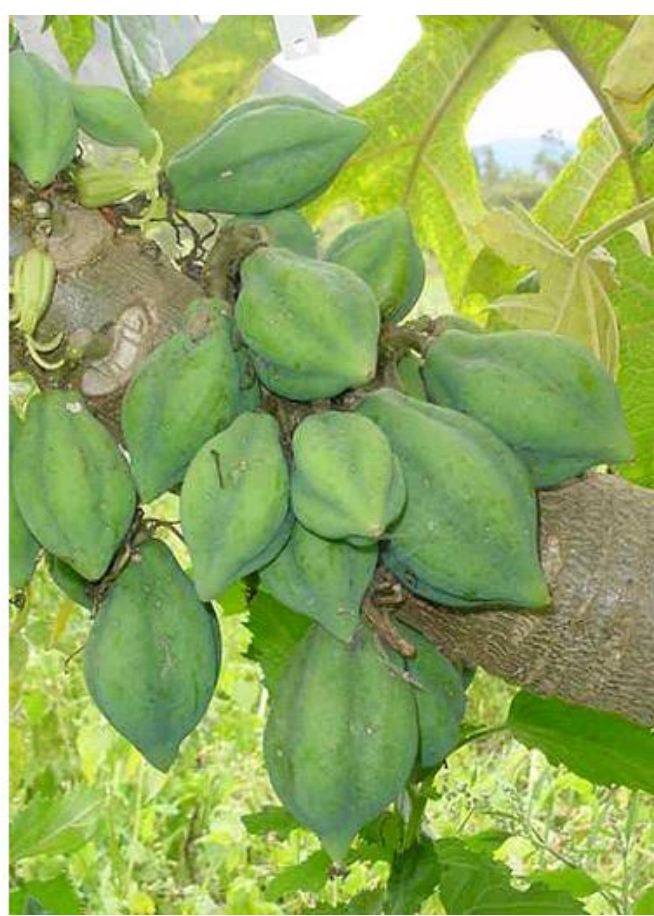

(a)

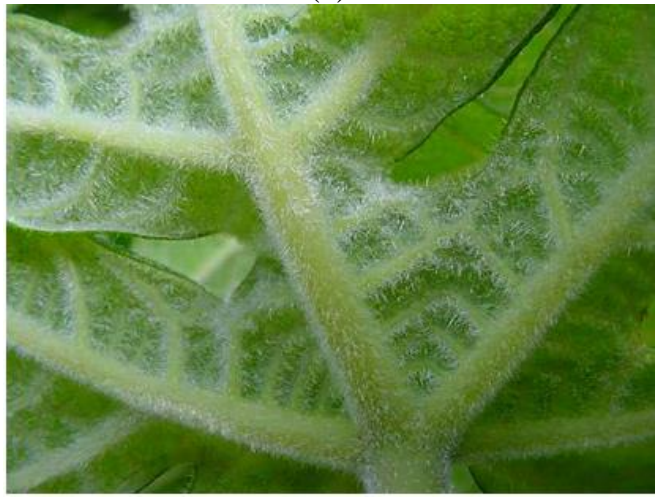

(c)

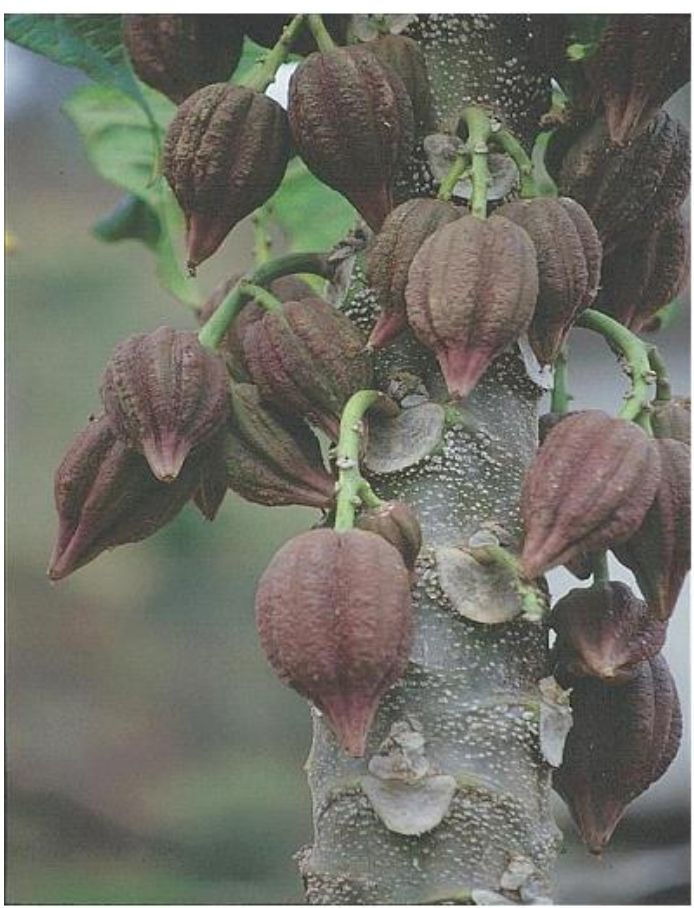

(b)

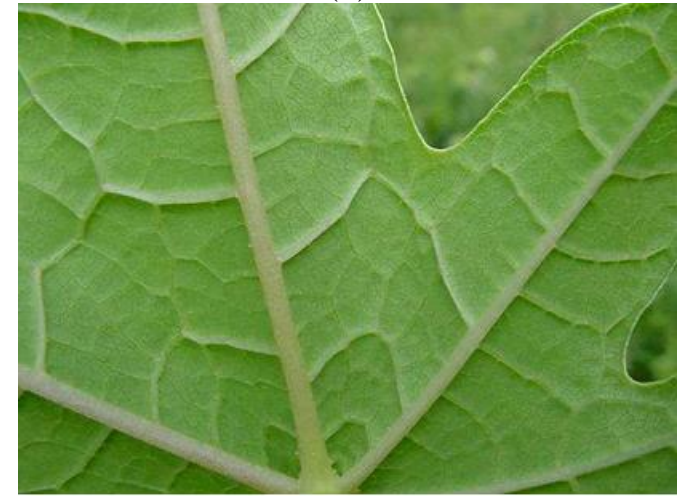

(d)

Fotografías de frutos y hojas de ejemplares pertenecientes a los Subgrupos B4 y B5 correspondientes a $V . s p$ (b) y (d) y $V$. cundinamarcensis (a) y (c), respectivamente. Nótese las diferencias en cuanto a presencia de pubescencia en el envés de la hoja y las diferencias en el fruto. 


\section{ANEXO 4}

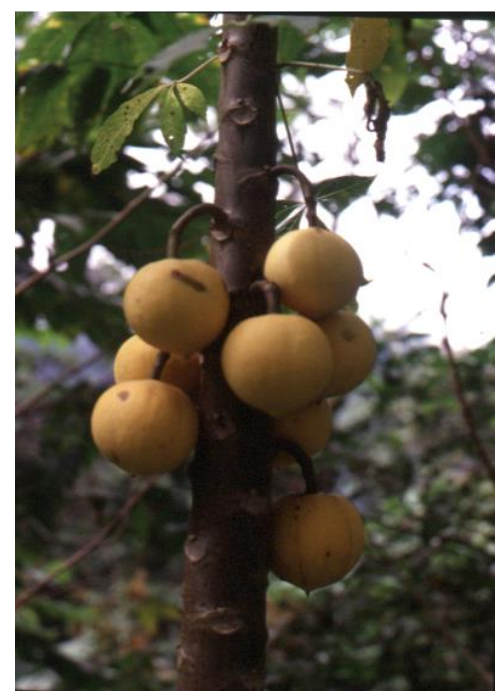

(a)

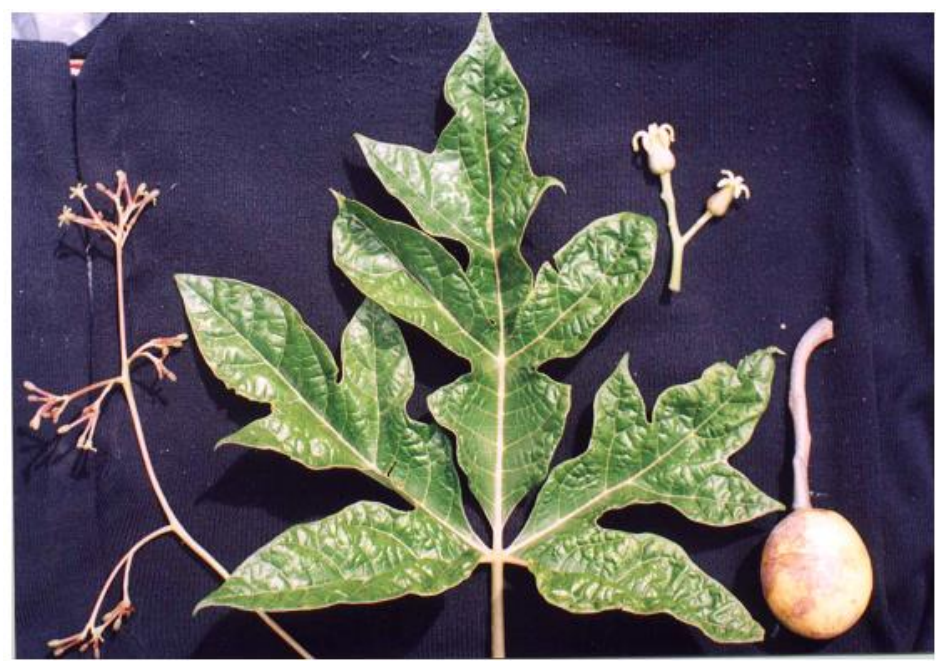

(b)

Fotos que muestran la similitud morfológica de los frutos de un ejemplar de $V$. palandensis (a) con respecto a $V$. goudotiana (b) pertenecientes al Subgrupo B11 en el dendrograma de la Figura 2. 